\title{
Manejo de Água para Estabelecimento de Alfafa (Medicago sativa L.) ${ }^{1}$
}

\author{
Joaquim Bartolomeu Rassini ${ }^{2}$, Edson José de Arruda Leme ${ }^{3}$
}

\begin{abstract}
RESUMO - O manejo de água para o desenvolvimento da alfafa cv. Crioula foi avaliado a campo, com a finalidade de verificar seus efeitos no estabelecimento da planta, até o $1^{\circ}$ corte, em 1997. Para isso, verificou-se o comportamento em três estádios de desenvolvimento (E1 = início do estádio vegetativo, E2 = vegetativo pleno e E3 = reprodutivo até colheita) em quatro níveis de água $(\mathrm{A}=100 \%, \mathrm{~B}=80 \%$, $\mathrm{C}=45-50 \%$ e $\mathrm{D}=20-25 \%$ de uma lâmina de irrigação por aspersão). Foram avaliados oito experimentos: 111, 110, 100, 101, 001, 011, 010, 000, em que o primeiro dígito se refere a E1; o segundo, a E2; e o terceiro, a E3. O valor 0 representa a época em que o estádio não recebeu água, coberto por uma estrututura móvel, que deslizava sobre trilhos, e também protegia contra precipitações pluviais casuais. O valor 1 refere-se à época em que houve aplicação dos níveis de água de irrigação. Os estádios de desenvolvimento da planta, em termos de rendimento de matéria seca, responderam de maneira diferente às condições hídricas, sendo E2 e E3 (planta estabelecida) os mais sensíveis e E1 (início do estádio vegetativo), o menos sensível, no qual a água foi prejudicial ao estabelecimento e rendimento da planta.
\end{abstract}

Palavras-chave: estádios de desenvolvimento, irrigação, matéria seca, níveis de água, rendimento de forragem

\section{Water Management for Alfalfa (Medicago sativa L. ) Establishment}

\begin{abstract}
The water management for growth of Crioula alfalfa cultivar was evaluated in a field study, in order to assess the effects in the plant establishment up to the first cut, at 1977. The study was carried out in 1997. So that, the behaviour at three growth stages $(E 1=$ early vegetative stage, $E 2=$ full vegetative stage, and E3 = reproductive stage until harvest $)$ in the presence of four water levels ( $\mathrm{A}=100 \%, \mathrm{~B}=80 \%, \mathrm{C}=45-50 \%$, and $\mathrm{D}=20-25 \%$ from a sprinkler irrigation) was studied. Eight combinations were evaluated: $111,110,100,101,001,011,010,000$, where the first digit is E1, the second is E2 and the third is E3. The number 0 in the figures represents the period in which growth stage did not receive water, cover by a mobile structure, which slide on trail, and also protected against occasional rainfall. The number 1 represents the time in which the irrigation water levels were applied. The growth stages of the plants as for dry matter yield, differently respond to the water conditions. The E2 and E3 were the most sensible to water supply and E1 the least sensible; in which the water was detrimental to the plant establishment and yield.
\end{abstract}

Key Words: dry matter, forage yield, growth stages, irrigation, water levels

\section{Introdução}

Na região Sudeste do Brasil, para garantir ou aumentar a produção agropecuária, a irrigação suplementar tem grande potencial. Nesta região, a precipitação natural nos meses chuvosos (novembro-março) é suficiente para que haja produção vegetal. Porém, freqüentemente, a falta de chuvas (veranicos) em estádios críticos do desenvolvimento das plantas resulta na redução qualitativa e quantitativa da produção. Ainda, o potencial para irrigação suplementar pode aumentar nesta região, uma vez que seu inverno pouco rigoroso permite o cultivo de espécies vegetais, que apenas têm seu desenvolvimento limitado pela falta de água. Este é o caso da alfafa (Medicago sativa $\mathrm{L}$.), que, em decorrência de sua variabilidade genética, pode ser cultivada em várias condições climáticas do mundo (BOLTON et al., 1972; HANSON et al., 1978; DEL POZO, 1983).

A alfafa, por ser uma planta forrageira com potencial para altos rendimentos (20 t MS/ha/ano) e de qualidade superior, se comparada com outras fontes de forragens, habitualmente utilizadas na pecuária do Brasil, como o milho, a cana-de-açúcar e o capim-elefante, tem se expandido para o Sudeste, em virtude da crescente implantação de sistemas intensivos de produção de leite na região, onde se encontram as maiores bacias leiteiras do país (VILELA, 1992). Nesta região, também, tem se observado que a produção de forragem de alfafa irrigada é maior na época da seca, durante abril a outubro (FONTES et al., 1993; RASSINI e FREITAS, 1995; BOTREL et al., 1996; EVANGELISTA et al., 1997). Essa característica é muito importante, uma vez que nessa época

1 Trabalho desenvolvido no Centro de Ciências Agrárias - UFSCar - Araras, SP.

2 Pesquisador da Embrapa Pecuária Sudeste, Caixa Postal 339, São Carlos, SP. CEP: 13560-970. E.mail: rassini@cppse.embrapa.br

3 Professor da UFSCar - CCA, Via Anhangüera, km 174, Caixa Postal 153, Araras, SP. CEP: $13600-970$. 
a produção das forrageiras tropicais é baixa, mesmo sob irrigação.

Apesar de grandes produtividades de alfafa obtidas em algumas regiões do Brasil, principalmente no Sul e Sudeste, o que já é reflexo do uso de tecnologias disponíveis (variedades, preparo do solo, calagem e adubação, época de semeadura, controle de invasoras etc), há necessidade de mais estudos sobre manejo da água de irrigação para a planta, pois, além de ser o principal fator para obter altos rendimentos com essa forrageira, é uma das práticas mais onerosas em um sistema de produção de alfafa (CEPEA/FEALQ, 1994; SANTOS, 1993; VILELA, 1992).

No Brasil, as pesquisas com irrigação desta forrageira apenas a consideram para a produção de feno (cultura irrigada). CUNHA et al. (1994), por exemplo, verificaram que a eficiência do uso de água pela alfafa cv. Crioula variou de 3,71 a 9,59 kg de MS/ha/mm. TASHIMA e KLAR (1997) concluíram que os maiores potenciais de água no solo permitiram melhor desenvolvimento vegetativo e produtividade atéo $5^{\circ}$ corte e, a partir deste, o processo se inverteu. COSSA e PEDRAS (1997) observaram queda de produção de matéria seca de alfafa, quando o potencial de água no solo permanecia entre -0,04 e -0,4 MPa.

Com base na importância da cultura da alfafa em sistemas intensivos de produção animal (carne e leite), o objetivo do presente estudo foi avaliar a relação entre diferentes estádios de desenvolvimento da planta e a aplicação de várias lâminas de água, visando estabelecer a cultura e obter produtividade máxima de um corte, a um adequado regime de água.

\section{Material e Métodos}

O experimento foi conduzido de 16/07 a 22/10/97, num Latossolo Vermelho Escuro, que antes havia sido cultivado com soja (Glycine max) por dois anos, com as seguintes características físico-químicas de 0 a $20 \mathrm{~cm}$ : argila $=290(\mathrm{~g} / \mathrm{kg})$, macroporos $=15(\%)$, $\mathrm{pH}\left(\mathrm{H}_{2} \mathrm{O}\right)=6,6, \mathrm{pH}\left(\mathrm{CaCl}_{2}\right)=6,2, \mathrm{M} . \mathrm{O} .=17\left(\mathrm{~g} / \mathrm{dm}^{3}\right)$, $\mathrm{P}=13\left(\mathrm{mg} / \mathrm{dm}^{3}\right), \mathrm{K}=3,4\left(\mathrm{nmol} / \mathrm{dm}^{3}\right), \mathrm{Ca}=$ $40\left(\mathrm{nmol} / \mathrm{dm}^{3}\right), \mathrm{Mg}=18\left(\mathrm{nmol} / \mathrm{dm}^{3}\right), \mathrm{Al}=$ $1\left(\mathrm{nmol} / \mathrm{dm}^{3}\right), \mathrm{CTC}=80\left(\mathrm{nmol} / \mathrm{dm}^{3}\right)$ e V $=77(\%)$.

Utilizou-se a alfafa cv. Crioula. O preparo do solo consistiu de uma aração e duas gradagens. A calagem foi realizada com distribuição a lanço de 2 t/ha de calcário dolomítico, visando elevar a saturação de bases a $80 \%$.

A semeadura foi realizada manualmente em 16/07/97, observando espaçamento de $30 \mathrm{~cm}$ entre linhas e densidade de $20 \mathrm{~kg}$ de sementes/ha. A adubação de manutenção da cultura, a lanço, em toda a parcela, foi equivalente a $150 \mathrm{~kg}$ de $\mathrm{P}_{2} \mathrm{O}_{5} / \mathrm{ha}, 130 \mathrm{~kg}$ de $\mathrm{K}_{2} \mathrm{O} / \mathrm{ha}$ e $30 \mathrm{~kg}$ de FTE BR-12/ha. As sementes foram inoculadas com estirpes de Rhizobium meliloti.

As avaliações da produção de matéria seca (MS) de alfafa foram realizadas em unidades experimentais de $2,4 \mathrm{~m}^{2}$ de área útil, com quatro níveis de irrigação por aspersão, em três estádios da cultura: E1 - início do estádio vegetativo (diferenciação foliar até afilho secundário); E2 - vegetativo pleno (afilho secundário até primeiros botões florais); E3 - reprodutivo (botões florais até primeiro corte: $10 \%$ de florescimento). Da semeadura até a diferenciação foliar, início do estádio E1, a cultura foi irrigada de modo uniforme. Além do rendimento de alfafa, por ocasião do corte, foram coletadas ao acaso cinco plantas em cada tratamento, para avaliar o desenvolvimento radicular e da parte aérea da planta.

Os quatro níveis de água de irrigação nos três estádios forneceram os seguintes tratamentos (experimentos ): 111, 110, 100, 101,001,011,010 e 000, em que 0 representa a época em que o estádio não recebeu água de irrigação e $\mathbf{1}$, o estádio em que houve aplicação dos quatro níveis de água para E1, E2 e E3, respectivamente. Estes experimentos possuíam uma cobertura montada sobre trilhos, para proteção contra precipitações pluviais casuais nas parcelas, com exceção do 000 (testemunha), que permaneceu sob condições normais do clima. Esse sistema de cobertura sempre foi acionado quando havia possibilidade de ocorrência de chuvas durante o dia e diariamente à noite. Logo ao amanhecer, as parcelas foram descobertas para a cultura receber a radiação solar plena. Deve-se salientar que o sistema de cobertura, constituído de uma estrutura de ferro, era de PVC flexível e transparente, a fim de evitar possíveis sombreamentos sobre a cultura.

Cada experimento correspondeu a uma área de $76,8 \mathrm{~m}^{2}$, formado por quatro partes iguais de $3,0 \times 6,4 \mathrm{~m}$, que constituíram os blocos. Por sua vez, cada bloco foi constituído de quatro parcelas de 1,6 x 3,0 m (1,0 x 2,4 =2,4 $\mathrm{m}^{2}$ de área útil), que receberam determinada lâmina de irrigação, conforme sua distância de afastamento da linha de aspersores. Com esse esquema, cada experimento foi delineado em blocos completos casualizados com quatro repetições, sendo duas de cada lado da linha de aspersão ("line source"). Portanto, resultaram da combinação de quatro lâminas de água em cada repetição: $1 \mathrm{~A}, 1 \mathrm{~B}, 1 \mathrm{C}, 1 \mathrm{D} ; 2 \mathrm{~A}$, 2B, 2C, 2D; 3A, 3B, 3C, 3D; 4A, 4B, 4C, 4D. Dessa 
312 Rev. bras. zootec.

forma, as parcelas distanciadas de 0 - 1,6 m, 1,6 - 3,2 m, 3,2 - 4,8 $\mathrm{m}$ e 4,8 - 6,0 $\mathrm{m}$ da linha de aspersores, corresponderam aos níveis de irrigação A, B, C e D, respectivamente. Nas Figuras 1 e 2, pode-se visualizar melhor a formação dos experimentos.

$\mathrm{O}$ tratamento com irrigação foi iniciado após a diferenciação foliar da planta de alfafa (início do estádio $\mathrm{E}_{1}$ ), por meio de dois aspersores por experimento, de giro completo Modelo SUPER MAMCAD, vazão de $2,4 \mathrm{~m}^{3} / \mathrm{h}$ e espaçamento de $12 \mathrm{~m}$. Os controles de pressão de serviço e taxa de aplicação foram realizados com manômetros e coletores (pluviômetros) instalados nas parcelas, conforme podese observar na Figura 2. O balanço hídrico do perfil do solo em cada experimento foi feito por meio de amostras de solo retiradas a cada dois dias, em que se determinou a umidade pelo método gravimétrico às profundidades de 0-20, 20-40 e 40-60 cm, no transcorrer do trabalho, em locais previamente estabelecidos (Figura 2).

Dependendo da condição de manejo da água nos experimentos (irrigação, precipitação pluvial e indução da deficiência hídrica pela cobertura), bem como da demanda evaporativa local, principalmente temperatura e umidade relativa do ar (Tabela 1), a aplicação de água foi realizada sempre que a planta consumia a água disponível no solo, que possuia um CAD (capacidade de água disponível) de 17 a $20 \mathrm{~mm}$ e limite inferior de 7 a $9 \mathrm{~mm}(\mathrm{PMP}=$ ponto de murcha permanente).

A análise de variância de cada experimento para o rendimento de matéria seca de alfafa seguiu as recomendações de PIMENTEL GOMES (1978). O conjunto desses oito experimentos foi estatisticamente avaliado em análise de grupos (PIMENTEL GOMES,

Tabela 1 - Temperatura $\left({ }^{\circ} \mathrm{C}\right)$ e umidade relativa do ar $(\%)^{1}$ Table 1 - Temperature $\left({ }^{\circ} \mathrm{C}\right)$ and relative air humidity (\%)

\begin{tabular}{|c|c|c|c|c|c|c|c|c|}
\hline \multirow[t]{2}{*}{$\begin{array}{l}\text { Dia } \\
\text { Day }\end{array}$} & \multicolumn{2}{|c|}{$\begin{array}{l}\text { Julho } \\
\text { July }\end{array}$} & \multicolumn{2}{|c|}{$\begin{array}{c}\text { Agosto } \\
\text { August }\end{array}$} & \multicolumn{2}{|c|}{$\begin{array}{l}\text { Setembro } \\
\text { September }\end{array}$} & \multicolumn{2}{|c|}{$\begin{array}{c}\text { Outubro } \\
\text { October }\end{array}$} \\
\hline & $\mathrm{T}$ & $\overline{\mathrm{UR}}$ & $\mathrm{T}$ & $\overline{\mathrm{UR}}$ & $\mathrm{T}$ & UR & $\mathrm{T}$ & UR \\
\hline 1 & 18,1 & 88 & 20,4 & 62 & 22,0 & 44 & 20,6 & 97 \\
\hline 2 & 18,7 & 69 & 20,6 & 60 & 23,3 & 41 & 20,6 & 69 \\
\hline 3 & 19,4 & 71 & 19,0 & 40 & 22,0 & 43 & 18,2 & 70 \\
\hline 4 & 19,8 & 75 & 20,2 & 71 & 23,4 & 44 & 20,6 & 62 \\
\hline 5 & 19,9 & 63 & 16,5 & 89 & 24,8 & 50 & 24,9 & 72 \\
\hline 6 & 19,0 & 81 & 19,3 & 62 & 22,4 & 70 & 24,5 & 93 \\
\hline 7 & 19,5 & 58 & 21,3 & 64 & 21,8 & 59 & 20,0 & 90 \\
\hline 8 & 18,6 & 53 & 15,0 & 85 & 24,5 & 51 & 20,0 & 83 \\
\hline 9 & 17,3 & 63 & 13,2 & 69 & 26,5 & 43 & 24,4 & 67 \\
\hline 10 & 18,5 & 67 & 14,8 & 51 & 23,3 & 67 & 23,6 & 62 \\
\hline 11 & 18,5 & 56 & 16,8 & 64 & 19,5 & 68 & 23,8 & 59 \\
\hline 12 & 19,2 & 67 & 18,0 & 44 & 23,8 & 55 & 25,7 & 55 \\
\hline 13 & 19,8 & 63 & 21,1 & 45 & 24,8 & 76 & 27,3 & 55 \\
\hline 14 & 18,3 & 59 & 17,7 & 51 & 23,0 & 96 & 25,9 & 56 \\
\hline 15 & 19,1 & 66 & 19,3 & 52 & 23,8 & 77 & 28,1 & 54 \\
\hline 16 & 19,6 & 68 & 17,8 & 50 & 19,9 & 55 & 25,3 & 99 \\
\hline 17 & 20,5 & 65 & 19,1 & 54 & 21,0 & 40 & 19,6 & 73 \\
\hline 18 & 19,8 & 56 & 20,0 & 55 & 19,9 & 54 & 20,9 & 89 \\
\hline 19 & 19,3 & 65 & 20,3 & 57 & 21,5 & 47 & 20,2 & 98 \\
\hline 20 & 19,8 & 72 & 21,0 & 60 & 18,8 & 91 & 21,3 & 98 \\
\hline 21 & 12,8 & 100 & 19,9 & 79 & 19,1 & 87 & 20,5 & 85 \\
\hline 22 & 16,6 & 82 & 21,6 & 61 & 20,0 & 66 & 19,9 & 79 \\
\hline 23 & 17,5 & 67 & 21,9 & 58 & 20,1 & 51 & 21,3 & 84 \\
\hline 24 & 17,3 & 68 & 18,2 & 81 & 23,2 & 68 & 20,2 & 94 \\
\hline 25 & 16,4 & 58 & 19,4 & 52 & 21,4 & 96 & 19,8 & 99 \\
\hline 26 & 16,9 & 59 & 19,0 & 42 & 21,3 & 93 & 20,8 & 84 \\
\hline 27 & 17,5 & 60 & 21,9 & 38 & 18,0 & 81 & 24,0 & 71 \\
\hline 28 & 19,1 & 59 & 21,6 & 44 & 23,8 & 75 & 24,9 & 63 \\
\hline 29 & 17,5 & 63 & 21,1 & 46 & 24,1 & 69 & 27,0 & 74 \\
\hline 30 & 17,6 & 65 & 21,5 & 41 & 23,5 & 72 & 26,2 & 95 \\
\hline 31 & 18,8 & 69 & 21,4 & 43 & & & 25,8 & 78 \\
\hline
\end{tabular}

${ }^{1}$ Médias obtidas de dados coletados três vezes ao dia: 9,15 e 21 horas (Averages from data collected three times a day: 9,15 and 21 hours). 
RASSINI e LEME

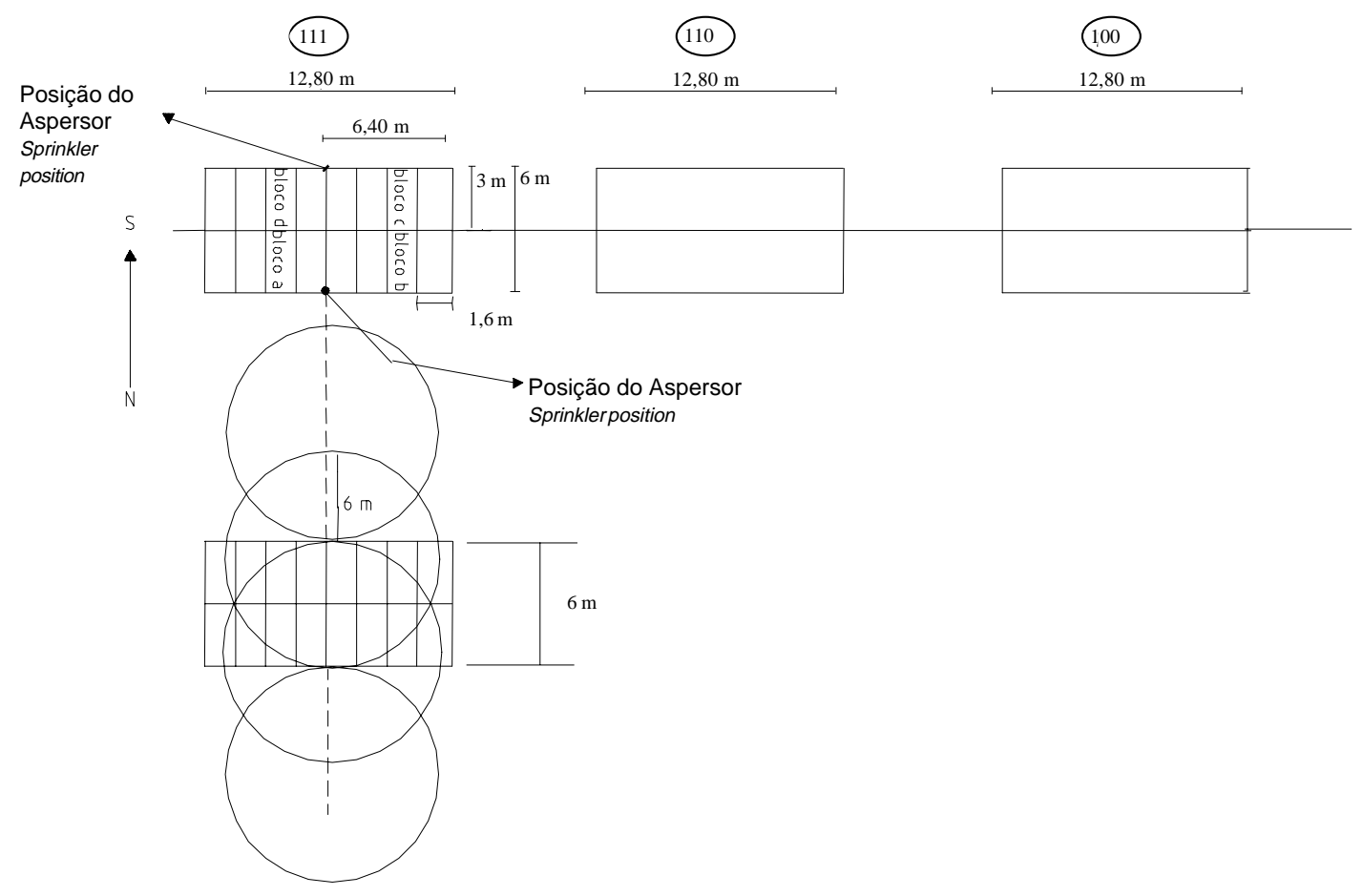

Figura 1 - Composição dos experimentos $(111,110,100 \ldots \ldots$ e 000$)$.

Figure 1 - Experiments composition $(111,110,100$............ and 000).

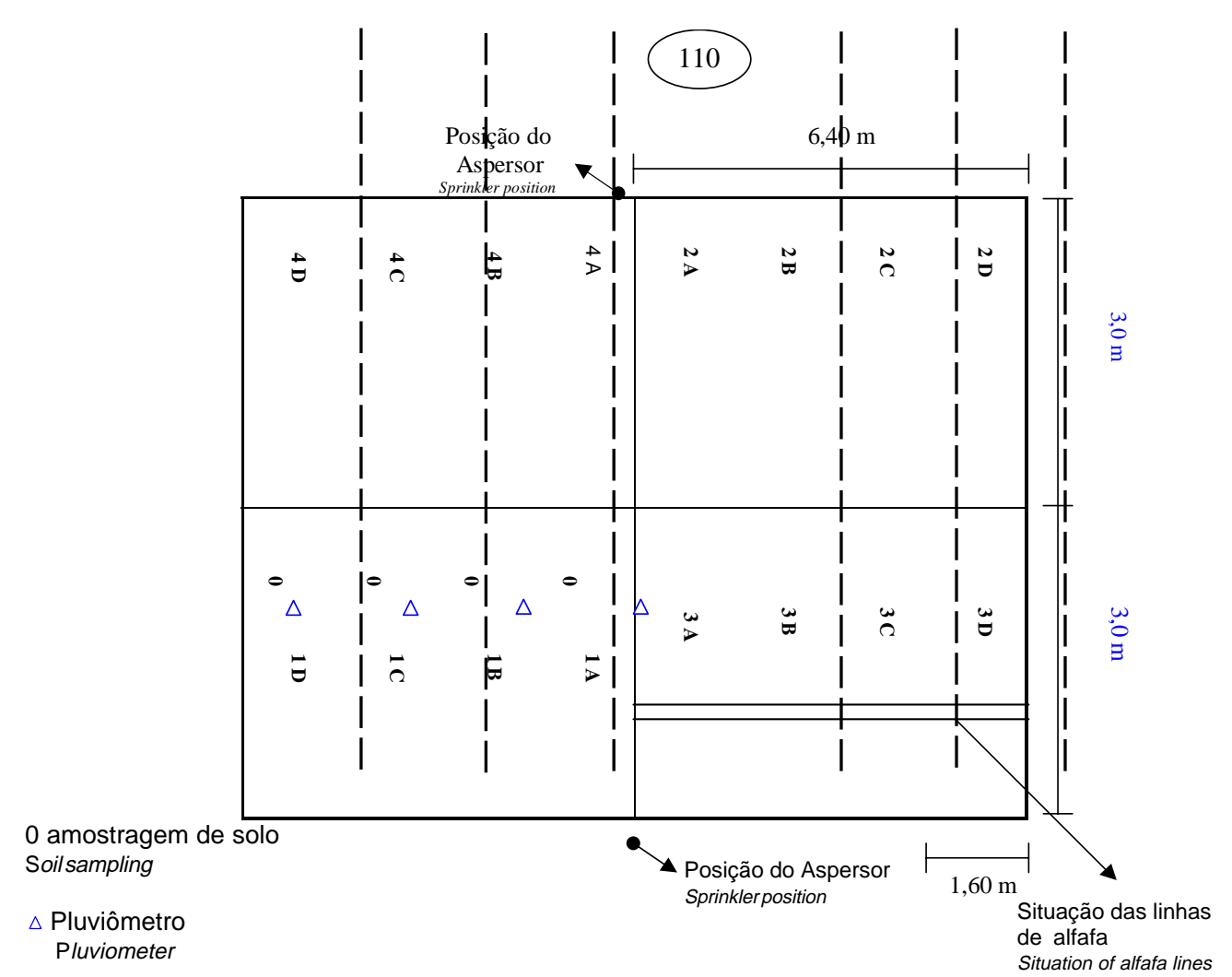

Figura 2 - Composição de um experimento (110, por exemplo).

Figure 2 - Composition of one experiment (110, per example). 
314 Rev. bras. zootec.

1978; LITTLE e HILLS, 1978; STEEL e TORRIE, 1980), procurando ajustar os graus de liberdade dos resíduos, conforme método recomendado por Cochran, citado por PIMENTEL GOMES (1978).

\section{Resultados e Discussão}

Os níveis de irrigação resultaram das lâminas de água aplicadas em cada parcela e estão expressos na Tabela 2, na qual também constam as ocorrências normais de precipitação pluvial. Em média, durante todo o período de estabelecimento da alfafa, esses níveis apresentaram o seguinte comportamento: $\mathrm{D}_{\mathrm{A}}=100 \%, \mathrm{D}_{\mathrm{B}}=80 \%, \mathrm{D}_{\mathrm{C}}=45-50 \%, \mathrm{D}_{\mathrm{D}}=20-25 \%$ de uma lâmina de irrigação, determinados conforme metodologia descrita anteriormente ("line source"). Observa-se ainda na Tabela 2 que as chuvas foram impedidas, conforme o tratamento, pelo uso da cobertura móvel, com exceção do tratamento testemunha, que permaneceu sob condições naturais do clima.

Na Tabela 3 estão apresentados os valores médios das produtividades de matéria seca de um corte de alfafa, em função de quatro níveis de irrigação em estádios de desenvolvimento da planta. A análise de

Tabela 2 - Distribuição de água durante o estabelecimento da alfafa Table 2 - Water distribution during alfalfa establishment

\begin{tabular}{|c|c|c|c|c|c|c|c|c|c|c|}
\hline \multirow[t]{3}{*}{ Trat. } & \multirow[t]{3}{*}{ NIR } & \multicolumn{4}{|c|}{$\begin{array}{l}\text { Irrigação }(\mathrm{mm}) \\
\text { Irrigation }\end{array}$} & \multicolumn{4}{|c|}{$\begin{array}{l}\text { Precipitação }(\mathrm{mm}) \\
\text { Precipitation }\end{array}$} & \multirow{3}{*}{$\begin{array}{c}\text { Água } \\
\text { total } \\
\text { Total } \\
\text { water }\end{array}$} \\
\hline & & \multicolumn{3}{|c|}{$\begin{array}{l}\text { Estádios } \\
\text { Stage }\end{array}$} & \multirow[t]{2}{*}{$\begin{array}{l}\text { EPA } \\
E P A\end{array}$} & \multicolumn{3}{|c|}{$\begin{array}{c}\text { Estádios } \\
\text { Stage }\end{array}$} & \multirow{2}{*}{$\begin{array}{c}\mathrm{EPA} \\
E P A \\
(\mathrm{~mm})\end{array}$} & \\
\hline & & 1 & 2 & 3 & & 1 & 2 & 3 & & \\
\hline & $\mathrm{D}_{\mathrm{A}}$ & 103,8 & 122,1 & 93,7 & 319,6 & 0 & 52,0 & 90,8 & 142,8 & 462,4 \\
\hline & $\mathrm{D}_{\mathrm{B}}^{\mathrm{A}}$ & 80,7 & 103,0 & 65,1 & 248,8 & 0 & 52,0 & 90,8 & 142,8 & 391,6 \\
\hline \multirow[t]{4}{*}{111} & $D_{C}$ & 41,3 & 57,4 & 36,4 & 135,1 & 0 & 52,0 & 90,8 & 142,8 & 277,9 \\
\hline & $\mathrm{D}_{\mathrm{D}}$ & 15,8 & 28,9 & 17,3 & 62,0 & 0 & 52,0 & 90,8 & 142,8 & 204,8 \\
\hline & $\mathrm{D}_{\mathrm{A}}$ & 85,0 & 113,4 & 0 & 198,4 & 0 & 52,0 & 0 & 52,0 & 250,4 \\
\hline & $\mathrm{D}_{\mathrm{B}}^{\mathrm{A}}$ & 62,2 & 106,7 & 0 & 168,9 & 0 & 52,0 & 0 & 52,0 & 220,9 \\
\hline \multirow[t]{4}{*}{110} & $\mathrm{D}_{\mathrm{C}}^{\mathrm{B}}$ & 37,0 & 76,9 & 0 & 113,9 & 0 & 52,0 & 0 & 52,0 & 165,9 \\
\hline & $\mathrm{D}_{\mathrm{D}}$ & 19,5 & 46,4 & 0 & 65,9 & 0 & 52,0 & 0 & 52,0 & 117,9 \\
\hline & $\mathrm{D}_{\mathrm{A}}$ & 79,5 & 0 & 0 & 79,5 & 0 & 0 & 0 & 0 & 79,5 \\
\hline & $\mathrm{D}_{\mathrm{B}}^{\mathrm{A}}$ & 55,9 & 0 & 0 & 55,9 & 0 & 0 & 0 & 0 & 55,9 \\
\hline \multirow[t]{4}{*}{100} & $\mathrm{D}_{\mathrm{C}}$ & 30,5 & 0 & 0 & 30,5 & 0 & 0 & 0 & 0 & 30,5 \\
\hline & $\mathrm{D}_{\mathrm{D}}^{\mathrm{C}}$ & 12,9 & 0 & 0 & 12,9 & 0 & 0 & 0 & 0 & 12,9 \\
\hline & $\mathrm{D}_{\mathrm{A}}^{\mathrm{D}}$ & 73,1 & 0 & 84,7 & 157,8 & 0 & 0 & 90,8 & 90,8 & 248,6 \\
\hline & $\mathrm{D}_{\mathrm{B}}^{\mathrm{A}}$ & 60,5 & 0 & 70,0 & 130,5 & 0 & 0 & 90,8 & 90,8 & 221,3 \\
\hline \multirow[t]{4}{*}{101} & $\mathrm{D}_{\mathrm{C}}$ & 35,2 & 0 & 39,6 & 74,8 & 0 & 0 & 90,8 & 90,8 & 165,6 \\
\hline & $\mathrm{D}_{\mathrm{D}}^{\mathrm{C}}$ & 19,4 & 0 & 13,9 & 33,3 & 0 & 0 & 90,8 & 90,8 & 124,1 \\
\hline & $\mathrm{D}_{\mathrm{A}}$ & 0 & 0 & 77,2 & 77,2 & 0 & 0 & 90,8 & 90,8 & 168,0 \\
\hline & $\mathrm{D}_{\mathrm{B}}^{\mathrm{A}}$ & 0 & 0 & 57,0 & 57,0 & 0 & 0 & 90,8 & 90,8 & 147,8 \\
\hline \multirow[t]{4}{*}{001} & $\mathrm{D}_{\mathrm{C}}$ & 0 & 0 & 25,8 & 25,8 & 0 & 0 & 90,8 & 90,8 & 116,6 \\
\hline & $\mathrm{D}_{\mathrm{D}}^{\mathrm{C}}$ & 0 & 0 & 9,1 & 9,1 & 0 & 0 & 90,8 & 90,8 & 99,9 \\
\hline & $\mathrm{D}_{\mathrm{A}}^{\mathrm{D}}$ & 0 & 152,0 & 82,7 & 234,7 & 0 & 52,0 & 90,8 & 142,8 & 377,5 \\
\hline & $\mathrm{D}_{\mathrm{B}}^{\mathrm{A}}$ & 0 & 126,0 & 67,8 & 193,8 & 0 & 52,0 & 90,8 & 142,8 & 336,6 \\
\hline \multirow[t]{4}{*}{011} & $D_{C}^{D}$ & 0 & 87,5 & 38,6 & 126,1 & 0 & 52,0 & 90,8 & 142,8 & 268,9 \\
\hline & $\mathrm{D}_{\mathrm{D}}$ & 0 & 35,0 & 15,6 & 50,6 & 0 & 52,0 & 90,8 & 142,8 & 193,4 \\
\hline & $\mathrm{D}_{\mathrm{A}}$ & 0 & 149,9 & 0 & 149,9 & 0 & 52,0 & 0 & 52,0 & 201,9 \\
\hline & $\mathrm{D}_{\mathrm{B}}^{\mathrm{A}}$ & 0 & 127,3 & 0 & 127,3 & 0 & 52,0 & 0 & 52,0 & 179,3 \\
\hline \multirow[t]{3}{*}{010} & $D_{C}^{D}$ & 0 & 95,0 & 0 & 95,0 & 0 & 52,0 & 0 & 52,0 & 147,0 \\
\hline & $\mathrm{D}_{\mathrm{D}}^{\mathrm{C}}$ & 0 & 45,0 & 0 & 45,0 & 0 & 52,0 & 0 & 52,0 & 97,0 \\
\hline & & & & & & 0 & 52,0 & 90,8 & 142,8 & 142,8 \\
\hline \multirow[t]{3}{*}{$000^{*}$} & & & & & & 0 & 52,0 & 90,8 & 142,8 & 142,8 \\
\hline & & & & & & 0 & 52,0 & 90,8 & 142,8 & 142,8 \\
\hline & & & & & & 0 & 52,0 & 90,8 & 142,8 & 142,8 \\
\hline
\end{tabular}

\footnotetext{
Trat - tratamentos 
variância mostrou efeito significativo $(\mathrm{P}<0,05)$ dos estádios de desenvolvimento (experimentos) e dos níveis de água, bem como da interação desses fatores.

As reduções dos níveis de água provocaram quedas de rendimento de matéria seca de alfafa em todos os experimentos, principalmente no estádio $\mathrm{E}_{2}$ (011 e 010), que foi mais sensível às condições hídricas. A maior produtividade ocorreu no experimento 011 , com $100 \%$ da lâmina de água de irrigação - $\mathrm{D}_{\mathrm{A}}, \operatorname{com} 3,10 \mathrm{t} / \mathrm{ha}$, e a menor no tratamento $100 \mathrm{com}$ $20 \%$ da lâmina de água - $\mathrm{D}_{\mathrm{D}}$, com 0,51 t/ha. Observa-se que, no maior déficit de água $\left(\mathrm{D}_{\mathrm{D}}\right)$, a produtividade de alfafa no tratamento 011 , de $1,52 \mathrm{t} / \mathrm{ha}$, não diferiu $(\mathrm{P}>0,05)$ das demais com $100 \%$ da lâmina de irrigação $\left(D_{A}\right)$ no $E 2$. Estes resultados evidenciam a sensibilidade da alfafa às condições hídricas, durante o período que vai do início do afilhamento secundário até a emissão dos primeiros botões florais (estádio vegetativo pleno), em conformidade com a recomendação do boletim 33 da FAO, que estabelece um valor de kc (coeficiente cultural) para alfafa de aproximadamente 0,4 no início do desenvolvimento da planta ou após o corte, aumentando para 1,05 a 1,20, antes do próximo corte, devido ao aumento das necessidades hídricas da cultura - ETm (DOORENBOS e KASSAN, 1994). No Rio Grande do Sul, CUNHA et al. (1994), também utilizando a cv. Crioula, verificaram que a evapotranspiração da planta variou de 1,7 (início do desenvolvimento) a 7,1 $\mathrm{mm} / \mathrm{dia}$ (estádio vegetativo pleno), com eficiência do uso de água variando de 3,71 a $9,59 \mathrm{~kg}$ de matéria seca/ha/mm.
As evidências da sensibilidade da alfafa às condições hídricas do solo, nos três diferentes estádios de desenvolvimento da planta, são mostradas nas Figuras 3 e 4, respectivamente, para o desenvolvimento da raiz e da parte aérea.

Verifica-se que os níveis de água permitiram maior desenvolvimento radicular, quando a irrigação foi aplicada nos estádios E2 e E3 (planta estabelecida). Por outro lado, a água no solo foi até prejudicial ao crescimento das raízes no início do estádio vegetativo $\left(\mathrm{E}_{1}\right)$, como se pode observar na Figura 3, pois os tratamentos com irrigação nesse período são bem semelhantes aos da testemunha (000). Por sua vez, nota-se na Figura 4 que o desenvolvimento da parte aérea foi coerente com a produção de matéria seca de alfafa, na qual se observa que a água aplicada no estádio $\mathrm{E}_{1}(\mathbf{1 1 0}, 100$ e 101) foi prejudicial à alfafa, com plantas menores que as do testemunha (000), principalmente no tratamento $\mathbf{1 0 0}$, mesmo considerando a menor quantidade de água no tratamento $\mathbf{1 0 0}$ em relação à testemunha $\mathbf{0 0 0}$, como decorrência das precipitações pluviais (Tabela 2). Esse fato inclusive vem reforçar a hipótese de que a água é prejudicial ao estabelecimento da alfafa, quando aplicada no início do estádio vegetativo, em função do menor desenvolvimento radicular da planta.

Os resultados do presente trabalho permitiram verificar que é variável a quantidade de água necessária nos vários estádios de desenvolvimento da alfafa, corroborando informações de DOVENA e SHOPSKI (1991), SMEAL et al. (1992) e MYER et al. (1993).

Tabela 3 - Manejo de água de irrigação e produção de um corte de alfafa (ton MS/ha) Table 3 - Irrigation water management and alfalfa yield (ton DM/ha)

\begin{tabular}{|c|c|c|c|c|c|c|c|c|c|}
\hline \multirow[t]{2}{*}{$\begin{array}{l}\text { Déficits } \\
\text { Deficit }\end{array}$} & \multicolumn{8}{|c|}{$\begin{array}{l}\text { Experimentos } \\
\text { Experiments }\end{array}$} & \multirow[t]{2}{*}{$\begin{array}{l}\text { Média } \\
\text { Mean }\end{array}$} \\
\hline & 111 & 110 & 100 & 101 & 001 & 011 & 010 & 000 & \\
\hline$\overline{\mathrm{D}_{\mathrm{A}}}$ & $1,64^{\mathrm{de}}$ & $1,51^{\mathrm{e}}$ & $1,18 \mathrm{~g}^{\mathrm{hij}}$ & $1,27^{\mathrm{gh}}$ & $1,46^{\mathrm{ef}}$ & $3,10^{\mathrm{a}}$ & $1,62^{\mathrm{de}}$ & $1,11^{\text {hijk }}$ & $1,61^{\mathrm{a}}$ \\
\hline $\mathrm{D}_{\mathrm{B}}^{\mathrm{A}}$ & $1,46^{\mathrm{ef}}$ & $1,22^{\text {ghi }}$ & $0,95^{\mathrm{k}}$ & $1,18^{\text {ghij }}$ & $1,59^{\mathrm{de}}$ & $2,90^{\mathrm{b}}$ & $1,76^{\mathrm{d}}$ & $0,98^{\mathrm{k}}$ & $1,50^{\mathrm{a}}$ \\
\hline $\mathrm{D}_{\mathrm{C}}^{\mathrm{B}}$ & $1,48^{\mathrm{ef}}$ & $1,13^{\text {ghij }}$ & $0,72^{1}$ & $1,02^{\mathrm{jk}}$ & $1,23 \mathrm{ghi}$ & $2,35^{\mathrm{c}}$ & $1,30^{\mathrm{fg}}$ & $1,11^{\text {hijk }}$ & $1,29^{b}$ \\
\hline $\mathrm{D}_{\mathrm{D}}^{\mathrm{C}}$ & $1,23^{\mathrm{ghi}}$ & $1,05^{\mathrm{ijk}}$ & $0,51^{\mathrm{m}}$ & $0,77^{1}$ & $1,03^{\mathrm{jk}}$ & $1,52^{\mathrm{e}}$ & $1,07^{\mathrm{ijk}}$ & $1,18^{\mathrm{ghij}}$ & $1,04^{\mathrm{c}}$ \\
\hline $\begin{array}{l}\text { Média } \\
\text { Mean }\end{array}$ & $1,45^{\mathrm{b}}$ & $1,23^{\mathrm{c}}$ & $0,84^{\mathrm{d}}$ & $1,06^{\mathrm{cd}}$ & $1,33^{b c}$ & $2,47^{\mathrm{a}}$ & $1,44^{\mathrm{b}}$ & $1,09^{\mathrm{cd}}$ & 1,36 \\
\hline
\end{tabular}

* Médias dos déficits de água, dos experimentos e da interação, com diferentes letras, são diferentes $(\mathrm{P}<0,05)$ pelo teste Tukey.

${ }^{*}$ * Means of water deficit, of the experiments and interaction, followed by different letters are different $(P<.05)$ by Tukey test. 
316 Rev. bras. zootec.

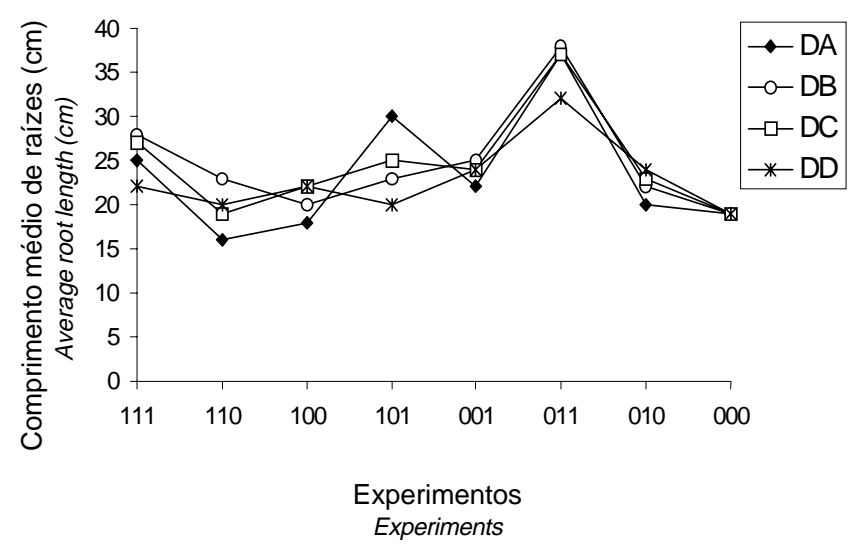

Figura 3 - Comprimento de raízes de alfafa, com o manejo da água de irrigação.

Figure 3 - Alfalfa root length, with irrigation water management.

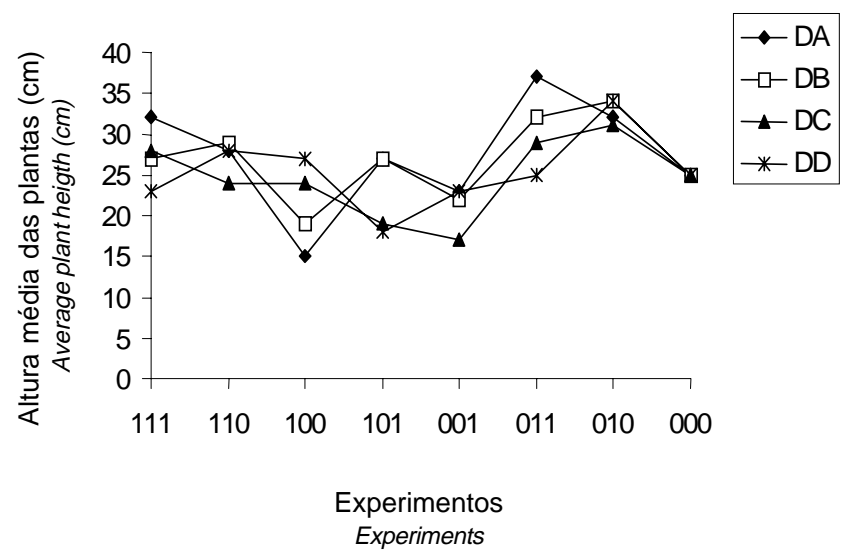

Figura 4 - Altura das plantas de alfafa, com o manejo da água de irrigação.

Figure 4 - Alfalfa plant height, with irrigation water management.

\section{Conclusões}

$\mathrm{Na}$ instalação da cultura de alfafa, ocorreu variação quanto à sensibilidade de três estádios de desenvolvimento da planta, a quatro níveis de irrigação. Quando já estava estabelecida (E2 e E3), houve grande sensibilidade às condições hídricas. Já no início do desenvolvimento (diferenciação foliar até afilho secundário), a cultura não foi sensível. Com a planta estabelecida, a redução dos níveis de irrigação acarretou queda de rendimento de matéria seca.

No início do estabelecimento da cultura (diferen- ciação foliar), a água aplicada foi prejudicial à alfafa, não permitindo bom desenvolvimento radiculare, conseqüentemente, da parte aérea da planta. Nessas circunstâncias, os rendimentos foram semelhantes aos do tratamento testemunha, ou até mesmo inferiores.

As condições hídricas variaram em relação aos estádios de desenvolvimento da alfafa, o que permite otimizar o consumo de água de irrigação durante seu cultivo, com a técnica de programação dinâmica (avaliação da quantidade ótima de água a ser aplicada nas culturas que possuem vários estádios de desenvolvimento).

\section{Referências Bibliográficas}

BOLTON, J.L., GOPLEN, B.P., BAENZIGER, A. 1972. World distribution and historical developments. In: HANSON, C.H.(Ed.) Alfalfa science and technology. Madison, Wisconsin: American Society of Agronomy. p.1-34.

BOTREL, M.A., ALVIM, M.J., XAVIER, D.F. Avaliação de cultivares de alfafa na Zona da Mata de Minas Gerais. In: REUNIÃO ANUAL DA SOCIEDADE BRASILEIRA DE ZOOTECNIA, 33, 1996, Fortaleza, CE, Anais... Fortaleza: SBZ, 1996. p.191-193.

CEPEA/FEALQ. Custo do Sistema de Irrigação por Aspersão para alfafa. Boletim do Leite, n.12, dez./1994.

COSSA, C.A., PEDRAS, J.F. Efeitos de três potenciais de água na produção de Medicago sativa L. In: REUNIÃO ANUAL DA SOCIEDADE BRASILEIRA DE ZOOTECNIA, 34, 1997, Juiz de Fora, MG, Anais...Juiz de Fora: SBZ, 1997.p.122-123.

CUNHA, G.R., PAULA, J.R.F., BERGAMASCHI, M. et al. 1994. Evapotranspiração e eficiência no uso de água em alfafa. Rev. Bras. Agromet., 2:23-27.

DEL POZO, M. 1983. La alfalfa: su cultivo y aprovechamiento. Madrid, Mundi- Prensa. 380p.

DONEVA, E., SHOPSKI, N. 1991. Control of the supply elements of soil water balance in the presence of shallow subsoil waters. Pochvoznamie i Agrokhimiya, 26(1-2):63-67.

DOORENBOS, J., KASSAM, A.H. 1994. Efeito da água no rendimento das culturas. FAO 33, traduzido pela UFPB, Campina Grande. 306p.

EVANGELISTA, A.R., MOULIN, A.F.V., GONÇALVES, F.G., et al. Avaliação de 34 cultivares de alfafa para o Sul de Minas Gerais. In: REUNIÃO ANUAL DA SOCIEDADE BRASILEIRA DE ZOOTECNIA, 34, 1997, Juiz de Fora, MG, Anais... Juiz de Fora: SBZ, 1997. p.68-70.

FONTES, P.C.R., MARTINS, C.E., COSER, A.C. et al. 1993. Produção e níveis de nutrientes em alfafa (Medicago sativa $\mathrm{L}$.) no primeiro ano de cultivo, na Zona da Mata de Minas Gerais. R. Soc. Bras. Zootec., 22(2):205-211.

HANSON, C.H., TYSDAL, H.M., DAVIS, R.L. 1978. Alfalfa. In: HUGHES, H.D., HEATH, M.E., METCALF, D.F. (Eds.) Forages: la ciência de la agricultura basada en la produccion de pastos. Mexico, Companhia Editorial Continental S.A. p.151-162.

LITTLE, T.M., HILLS, F.L. 1978. Agricultural experimentation design analysis. New York: John Willey \& Sons Inc. 350p.

MYER, G.L., MILLER, W.W., ZHENG, Y.B. 1993. Water management for profit maximization. J. Prod. Agric., 6(4):542-545. 
PIMENTEL GOMES, F. 1978. Curso de estatística experimental. 8.ed., Piracicaba: ESALQ-USP. 430p.

RASSINI, J.B., FREITAS, A.R. 1995. Efeitos da interferência de plantas daninhas no rendimento da cultura de alfafa (Medicago sativa L.) R. Soc. Bras. Zootec., 24(4):502-509.

SANTOS, J.A. 1993. Alfafa é mais proteína e energia a custo menor. Balde Branco, p.30-34.

SMEAL, D., KALLSEN, C.E., SAMMIS, T.W. 1991. Alfalfa yield as related to transpiration, growth stage and environment. Irrigation Sci., 12(2):79-86.

SMEAL, D., GREORY, E.J., ARNOLD, R.N. 1992. Interseasonal variability in the water use production function of alfalfa. J. Prod. Agric., 5(4):576-580.

STEEL, R.G.D., TORRIE, J.H. 1980. Principles and procedures of statistics a biometrical approach. Mc Grow. Hill Book Company. New York. 633p.
TASHIMA, H., KLAR, A.E. 1997. Níveis de água e doses de potássio no desenvolvimento vegetativo e na produtividade da alfafa (Medicago sativa L.). IRRIGA, 2(1) (resumo das dissertações - 1996):2.

VILELA, D. 1992. Potencialidade da alfafa na região Sudeste do Brasil. Inf. Agropec., 16(175):50-53.

Recebido em: 27/10/98

Aceito em: 16/10/00 